\title{
Prevention of atherosclerotic complications: controlled trial of ketanserin
}

\author{
Prevention of Atherosclerotic Complications with Ketanserin Trial Group
}

\begin{abstract}
Study objective-To determine whether ketanserin, an antagonist at the serotonin receptor, prevents important vascular events such as death, myocardial infarction, major stroke, and amputation of a leg in patients with claudication.
\end{abstract}

Design-Double blind, randomised, placebo controlled trial after a single blind run in period of placebo treatment for one month.

Setting-One hundred and forty seven outpatient clinics in 14 countries.

Patients - Total of 3899 patients over 40 years old who had had documented intermittent claudication for at least two months and in whom the ratio of systolic blood pressure in the ankle to that in the arm was $\leqslant \mathbf{0 . 8 5}$ in both arteries of at least one foot.

Intervention-After the one month placebo run in period patients were randomly allocated to take $20 \mathrm{mg}$ ketanserin three times daily for the first month and $\mathbf{4 0} \mathrm{mg}$ three times daily thereafter or to take the same number of placebo tablets. Five months after the onset of the trial, on the recommendation of the ethical and safety committee, four patients stopped taking ketanserin and two stopped taking placebo because they had a corrected QT interval $>500 \mathrm{~ms}$. Four months later the committee recommended that all patients taking diuretics should stop receiving trial treatment (167 of those taking ketanserin and 144 of those taking placebo).

End point-The first primary event after randomisation. Primary events were definite myocardial infarction, major stroke, amputation above the ankle, excision of ischaemic viscera, and death due to other vascular causes.

Measurements and main results-There were 136 study end points in the 1930 patients treated with ketanserin, who were followed up for 2063 patient years, and 132 study end points in the 1969 patients treated with placebo, who were followed up for 2129 patient years. A harmful interaction of ketanserin and potassium losing diuretics resulted in an increase in the number of deaths. After patients taking potassium losing diuretics or antiarrhythmic agents were included a secondary analysis showed that there were 65 end points in 1514 patients taking ketanserin and 87 in 1557 patients taking placebo, a reduction of $23 \%$ in the number of study end points in those taking ketanserin.

Conclusions-Ketanserin can prolong the corrected QT interval, and the combined use of ketanserin and potassium losing diuretics can be harmful. A secondary analysis suggested a protective effect of ketanserin against cardiovascular complications in patients with claudication.

Correspondence and

requests for reprints to:

Professor $M$ Verstraete,

Centre for Thrombosis and

Vascular Research,

Department of Medical

Research, University of

Leuven, 3000 Leuven,

Belgium.

BrMed f 1989;298:424-30 vasoconstrictor, especially in the presence of atheroma or endothelial damage, ${ }^{3}$ and this effect may also be important in thrombosis.

Ketanserin is an antagonist at the $S_{2}$ serotonin receptor $^{4}$ and therefore inhibits platelet aggregation induced by serotonin. It also improves haemorrheological properties, particularly blood filterability'; has an antihypertensive effect ${ }^{6}$; and has had contradictory effects on walking distance in patients with claudication. ${ }^{7}$ In one study it was associated with a considerable reduction in important cardiovascular events. ${ }^{8}$

The prevention of atherosclerotic complications with ketanserin (PACK) trial was conducted in patients with atherosclerosis causing intermittent claudication. The aim of the trial was to determine whether ketanserin prevents important vascular events such as death, myocardial infarction, major stroke, and amputation of a leg or excision of ischaemic viscera in a population in which such events are fairly common. ${ }^{910}$

\section{Patients and methods}

The trial was a randomised, placebo controlled, double blind study conducted in 147 centres in 14 countries. After a single blind run in period of one month of placebo treatment, patients were randomly allocated to receive either ketanserin or matching placebo. For the first month the dose of ketanserin was $20 \mathrm{mg}$ three times daily, and thereafter it was $40 \mathrm{mg}$ three times daily.

\section{PATIENTS}

Men and non-pregnant women over 40 years old who had had intermittent claudication for at least two months were selected for the trial. Claudication was defined as leg pain on walking that resolved in less than five minutes on standing. In addition the ratio of the systolic blood pressure in the ankle to that in the arm had to be $\leqslant 0.85$ in both arteries of at least one foot at the time of selection and at randomisation. Patients with a previous history of claudication who had had an amputation, reconstructive vascular surgery, transluminal angioplasty, or regional thrombolytic treatment more than three months before randomisation were also admitted to the trial. Patients with severe ischaemic pain at rest, incipient gangrene, unstable angina, serious kidney dysfunction (serum creatinine concentration $>250 \mu \mathrm{mol} / \mathrm{l}$ ), or other conditions resulting in a life expectancy of less than two years were not included. Patients taking $\beta$ blockers, dipyridamole, ticlopidine, or aspirin were included in the study only if these drugs could be stopped gradually during the run in period. Patients were allowed to continue taking diuretics. Those who had a definite myocardial infarction, major stroke, or amputation of a leg above the ankle during the run in period were not randomised.

All randomised patients were seen after the first and third months and subsequently at intervals of three months. At each visit blood pressure was recorded and the patient was questioned for possible 
adverse reactions. Blood was sampled at randomisation and after 12 months of treatment for routine haematological and biochemical testing. In 28 selected centres (with a total of 594 patients) the walking distance needed to elicit leg pain was measured on a treadmill at randomisation and after six and 12 months of treatment.

\section{DEFINITIONS}

The following vascular complications were considered to be primary events: definite myocardial infarction, major stroke (acute neurological deficit lasting more than one week), amputation above the ankle for reasons other than trauma or tumour, excision of ischaemic viscera, and death from other vascular causes (any death that could not be ascribed definitely to a non-vascular cause); any sudden death was considered to be due to a vascular cause unless proved otherwise at necropsy. Myocardial infarction, stroke, amputation, and excision of ischaemic viscera were considered to be fatal if death occurred within one month of the event.

The following vascular complications were considered to be secondary events: probable or possible myocardial infarction, recently developed angina or unstable angina, stroke other than major stroke, retinal artery occlusion, definite transient ischaemic attack, deep vein thrombosis, pulmonary embolism, recently developed renal failure or severe hypertension, and deterioration of obliterative arterial disease leading to a procedure such as surgery or angioplasty.

Each primary or secondary event was defined precisely in the protocol. The first primary event after randomisation was the study end point. Each patient could contribute only one study end point in the intention to treat analysis. Primary events after a study end point and all secondary events were recorded. After the study was completed deaths were classified as sudden or non-sudden. "Hypertension was defined as a systolic pressure $\geqslant 160 \mathrm{~mm} \mathrm{Hg}$ or a diastolic pressure $\geqslant 95 \mathrm{~mm} \mathrm{Hg}$, or both, irrespective of treatment. Mean blood pressure was defined as diastolic pressure plus one third of pulse pressure.

\section{RANDOMISATION AND MANAGEMENT OF DATA}

Patients satisfying the criteria for selection after the run in period randomly received coded tablets of either ketanserin or placebo; the appearance and taste of the tablets were identical. Randomisation numbers were generated on a computer and balanced in blocks of 10 per investigator. The centres sent data on primary and secondary events to their national coordinator, who checked and completed the information before it was forwarded to the coordinating centre at the University of Leuven and to the statistics centre at the University of Glasgow. After full documentation of an event the four members of the executive committee reviewed and validated it and then sent the information to Dr G Murray at the statistics centre. He was the only one to know the treatment code, and he transmitted the decoded results to the chairman of the ethical and safety committee.

The record forms containing all the other information on the patients were checked by a monitor at the Janssen Research Foundation and posted to the data management and processing centre. The statistics centre undertook an independent audit of the data entered by the data management and processing centre. The sponsoring company was not represented in the coordinating centre or at any committee dealing with the recording of events. A member of the executive committee visited one third of the centres to check adherence to the protocol and the accuracy of entering data.

\section{STATISTICAL METHODS AND ANALYSIS}

We decided how many patients to include in the trial on the basis of the following assumptions: if the grouped rate of end points with placebo was $10 \%$ per year and ketanserin reduced this by one third 2200 patients had to enter the one year trial to achieve a $5 \%$ level of significance with a power of $80 \%$ (two tailed). As non-compliance among the patients taking ketanserin (set at $20 \%$ ) could dilute the magnitude of any protective effect of the drug the number of patients had to be increased to 3400 . Grouped study end points in patients who were randomised in the two treatment groups were compared on an intention to treat basis (each patient remaining in the treatment group to which he or she had been allocated originally) with a log rank test. The effects of prognostic factors and their interaction with ketanserin and placebo were investigated with the proportional hazards regression model. In further analyses of only those patients who received the trial treatment all events occurring after the treatment was stopped were disregarded.

For analysis of primary and secondary events patients were considered to be receiving the trial drug up to 30 days after it was stopped. For analysis of interactions between ketanserin and diuretics or antiarrhythmic drugs patients were considered to be receiving the trial drug up to one week after it was stopped. Patients whose trial drug was stopped were followed up until the end of the trial.

\section{ETHICAL PROCEDURES}

The trial was conducted in accordance with the Declaration of Helsinki, and the approval of the local ethical committees was obtained in each centre. The progress of the trial was monitored by an independent ethical and safety committee.

\section{Results}

A total of 3899 patients was randomly allocated to receive either ketanserin or placebo. The first patient was randomised on 21 November 1985 and the last on 22 August 1986. Eight patients (four in each group) were lost to follow up. The characteristics of patients in both groups were similar at the time of randomisation (table I).

Five months after the onset of the trial the ethical and safety committee noted the occurrence of reversible disturbances of cardiac rhythm in those taking ketanserin. As ketanserin prolongs the corrected QT interval in an electrocardiogram the committee recommended that another electrocardiogram should be recorded in all patients who at randomisation had a plasma potassium concentration $<3.0 \mu \mathrm{mol} / \mathrm{l}$; had a second or third degree heart block; had a corrected QT interval $>500 \mathrm{~ms}$; or were being treated electively with an antiarrhythmic drug. The committee recommended that any patient found to have a corrected QT interval $>500$ ms should stop taking the trial drug; as a result four patients stopped taking ketanserin and two patients stopped taking placebo.

Four months later the ethical and safety committee, concerned about an apparent excess of deaths in patients treated simultaneously with ketanserin and diuretics, recommended that such a combination of treatment should be stopped. As a result 167 patients stopped taking ketanserin and 144 stopped taking placebo. Because of this withdrawal of patients taking diuretics we performed two different analyses of the results. Firstly, we analysed the results as intended in the protocol (intention to treat analysis), and, secondly, we analysed the results excluding those for patients who took potassium losing diuretics or antiarrhythmics at any time. 


\begin{tabular}{|c|c|c|}
\hline & $\begin{array}{c}\text { Ketanserin } \\
(n=1930)\end{array}$ & $\begin{array}{c}\text { Placebo } \\
(n=1969)\end{array}$ \\
\hline Mean (SD) age (years) & $63 \cdot 3(9 \cdot 1)$ & $63 \cdot 2(9 \cdot 1)$ \\
\hline No (\%) male & $1508(78)$ & $1572(80)$ \\
\hline Mean (SD) mean arterial pressure $(\mathrm{mm} \mathrm{Hg}$ ) & $108(14)$ & $107(13)$ \\
\hline No (\%) with mean arterial pressure $>120 \mathrm{~mm} \mathrm{Hg}$ & $302(16)$ & $275(14)$ \\
\hline No (\%) with ratio of ankle:arm systolic blood pressure $<0.5$ & $338(18)$ & $316(16)$ \\
\hline No (\%) with ankle systolic blood pressure $<70 \mathrm{~mm} \mathrm{Hg}$ & $218(11)$ & $189(10)$ \\
\hline No $(\%)$ white & $1890(98)$ & $1922(98)$ \\
\hline No (\%) regular smokers & $787(41)$ & $797(40)$ \\
\hline No (\%) with hypertension* & $901(47)$ & $893(45)$ \\
\hline No (\%) with ratio of ankle:arm systolic blood pressure $>0.85$ & $173(9)$ & $189(10)$ \\
\hline No $(\%)$ with diabetes & $276(14)$ & $277(14)$ \\
\hline No (\%) with coronary disease & $494(26)$ & $539(27)$ \\
\hline No $(\%)$ with cerebrovascular disease & $191(10)$ & $168(9)$ \\
\hline No $(\%)$ who had had leg surgery for arterial disease & $772(40)$ & $785(40)$ \\
\hline \multicolumn{3}{|l|}{ No (\%) taking other drugs concomitantly: } \\
\hline None & $458(24)$ & $537(27)$ \\
\hline Digitalis & $162(8)$ & $166(8)$ \\
\hline Antiarrhythmics & 47 (2) & $47(2)$ \\
\hline Antianginals & $404(21)$ & $411(21)$ \\
\hline Anticoagulants & $165(9)$ & $172(9)$ \\
\hline Antidiabetics & $200(10)$ & $201(10)$ \\
\hline Diuretics & $455(24)$ & $444(23)$ \\
\hline Other antihypertensives & $240(12)$ & $256(13)$ \\
\hline \multicolumn{3}{|l|}{ Results of electrocardiography: } \\
\hline No $(\%)$ normal & $1002(52)$ & $1051(53)$ \\
\hline No (\%) showing myocardial infarction & $194(10)$ & $203(10)$ \\
\hline
\end{tabular}

*Systolic blood pressure $\geqslant 160 \mathrm{~mm} \mathrm{Hg}$ or diastolic blood pressure $\geqslant 95 \mathrm{~mm} \mathrm{Hg}$, or both.

INTENTION TO TREAT ANALYSIS OF STUDY END POINTS

Table II shows the results of the trial with patients in their allocated treatment groups whether or not they continued to receive the trial treatment. There were 136 study end points among the 1930 patients taking ketanserin, who were followed up for 2063 patient years, and 132 study end points in the 1969 patients taking placebo, who were followed up for 2129 patient years. The observed rate of end points in the ketanserin group was $106 \%$ of that in the placebo group (95\% confidence interval $83 \%$ to $134 \%$ ) (fig 1 (top)). A multivariate analysis that adjusted for the effect of

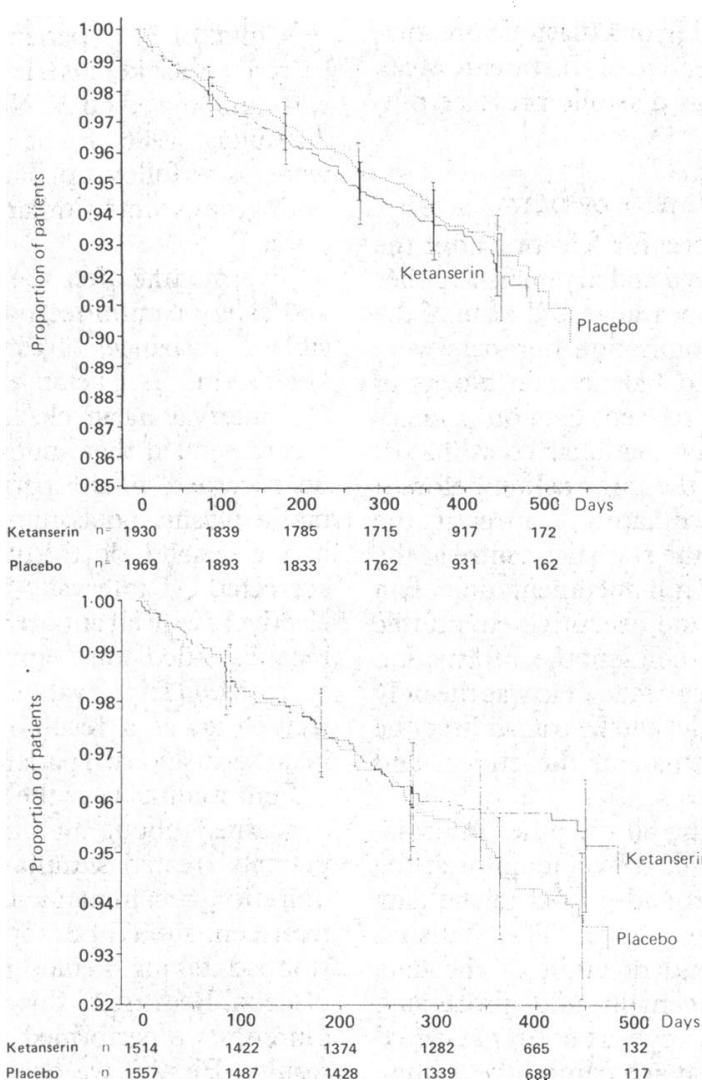

FIG 1-Proportion of patients surviving without study end point. Top: Intention to treat analysis. Bottom: Analysis of patients receiving trial treatment excluding patients taking potassium losing diuretics and antiarrhythmic drugs at any time during the study. Bars show $95 \%$ confidence intervals. Log rank $\chi^{2}=2 \cdot 44, d f=1, p=0 \cdot 119$ slight imbalances in baseline characteristics (table I) did not alter this finding.

By intention to treat analysis there was therefore no evidence to suggest that ketanserin provided any protective effect against study end points.

\section{INTENTION TO TREAT ANALYSIS OF EVENTS}

Table II shows that similar numbers of patients in each treatment group suffered fatal or non-fatal definite myocardial infarction or major strokes, but fewer patients in the ketanserin group had an amputation above the ankle (17 $v 29)$. Fifty six patients in the ketanserin group died from conditions that did not fulfil the trial definitions of myocardial infarction, stroke, or amputation but could also not be identified as non-vascular and so they were categorised as dying from other vascular causes. There were 41 such deaths among the patients in the placebo group. There were 23 deaths from non-vascular causes in the ketanserin group and 28 in the placebo group, so the total number of deaths in the two groups was 104 and 92, respectively. Thus the overall mortality in the patients taking ketanserin was $117 \%$ of that in the patients taking placebo ( $95 \%$ confidence interval $88 \%$ to $154 \%$ ).

TABLE II - Intention to treat analysis of study end points and deaths in patients taking ketanserin and placebo

\begin{tabular}{|c|c|c|}
\hline & $\underset{(n=1930)}{\text { Ketanserin }}$ & $\begin{array}{c}\text { Placebo } \\
(\mathrm{n}=1969)\end{array}$ \\
\hline \multicolumn{3}{|c|}{ Study end points } \\
\hline $\begin{array}{l}\text { Definite myocardial infarction } \\
\text { Major stroke }^{\star} \\
\text { Amputation }^{\star} \\
\text { Excision of ischaemic viscera } \\
\text { Other vascular causes of death }\end{array}$ & $\begin{array}{r}33 \\
25 \\
17 \\
5 \\
56\end{array}$ & $\begin{array}{r}36 \\
25 \\
29 \\
1 \\
41\end{array}$ \\
\hline Total & 136 & 132. \\
\hline \multicolumn{3}{|c|}{ Deaths } \\
\hline $\begin{array}{l}\text { Vascular } \\
\text { Non-vascular: } \\
\text { Cancer } \\
\text { Infection } \\
\text { Suicide } \\
\text { Other }\end{array}$ & $\begin{array}{rr} & 81 \\
13 & 23 \\
6 & \\
2 & \\
2 & \end{array}$ & $\begin{array}{rr} & 64 \\
22 & 28 \\
4 & \\
1 & \\
1 & \end{array}$ \\
\hline Total & 104 & 92 \\
\hline
\end{tabular}

^Fatal and non-fatal.

Table III shows the number of patients in each group who had a primary or secondary event in each category. Altogether 346 patients in the ketanserin group had at least one event or died, compared with 350 in the placebo group. The total number of primary and secondary events, including deaths, was 436 and 474 , respectively.

\section{SECONDARY ANALYSIS: INTERACTION WITH DIURETICS}

After the trial was completed a series of analyses not envisaged in the original protocol was performed to investigate the apparently harmful interaction of ketanserin with diuretics.

The patients taking diuretics were divided into two groups according to the type of diuretic. Those taking potassium sparing diuretics (amiloride, triamterene, spironolactone, and canrenoate) either alone or in combination with another diuretic were grouped separately from those taking all other diuretics, which were considered to be potassium losing whether or not potassium supplements were given. Mortality from all causes was analysed on an intention to treat basis with diuretics that were taken at the time of randomisation.

The total mortality in the three subgroups in the ketanserin group compared with the placebo group was $88 \%$ for those not taking diuretics, $95 \%$ for those taking potassium sparing diuretics, and $244 \%$ for those taking potassium losing diuretics (table IV). A 
TABLE III - Number of patients taking ketanserin and placebo with study end points and primary or secondary events

\begin{tabular}{|c|c|c|c|c|}
\hline & \multicolumn{2}{|c|}{ Intention to treat analysis } & \multicolumn{2}{|c|}{ Subgroup analysis* } \\
\hline & $\begin{array}{c}\text { Ketanserin } \\
(\mathrm{n}=1930)\end{array}$ & $\begin{array}{c}\text { Placebo } \\
(\mathrm{n}=1969)\end{array}$ & $\begin{array}{c}\text { Ketanserin } \\
(\mathrm{n}=1514)\end{array}$ & $\begin{array}{c}\text { Placebo } \\
(\mathrm{n}=1557)\end{array}$ \\
\hline Deaths & 104 & 92 & 46 & 61 \\
\hline Vascular & 81 & 64 & 34 & 45 \\
\hline Non-vascular & 23 & 28 & 12 & 16 \\
\hline Patients with study end point & 136 & 132 & 65 & 87 \\
\hline \multicolumn{5}{|l|}{ Patients who had at least one of following primary events: } \\
\hline Definite myocardial infarction & 34 & 36 & 15 & 23 \\
\hline Major stroke & 28 & 27 & 21 & 23 \\
\hline Amputation above ankle & 17 & 32 & 8 & 14 \\
\hline Excision of ischemic viscera & 5 & 1 & 3 & 1 \\
\hline Other vascular causes of death & 57 & 43 & 20 & 28 \\
\hline Patients who had at least one secondary event & 217 & 226 & 131 & 165 \\
\hline \multicolumn{5}{|l|}{ Patients who had at least one of following secondary events: } \\
\hline Probable myocardial infarction & 21 & 15 & 12 & 9 \\
\hline Unstable angina & 20 & 11 & 9 & 9 \\
\hline Newly developed angina & 13 & 6 & 8 & 6 \\
\hline Non-major stroke & 20 & 16 & 10 & 14 \\
\hline Retinal artery occlusion & 3 & 4 & 1 & 3 \\
\hline Transient ischaemic attack & 22 & 27 & 12 & 21 \\
\hline Deep vein thrombosis & 7 & 9 & 2 & 8 \\
\hline Pulmonary embolism & 3 & 3 & 1 & 3 \\
\hline Renal failure & & 3 & & \\
\hline Severe hypertension & 17 & 40 & 6 & 31 \\
\hline Deteriorating arterial disease & 103 & 111 & 72 & 75 \\
\hline \multirow{2}{*}{$\begin{array}{l}\text { Patients who died or had one or more primary or secondary } \\
\text { events } \dagger\end{array}$} & & & & \\
\hline & 346 & 350 & 196 & 249 \\
\hline
\end{tabular}

*In patients receiving trial treatment after exclusion of patients who took a potassium losing diuretic or an antiarrhythmic, or both, at any time during study.

†Patients with multiple events were counted once.

test showed a significant statistical interaction $\left(\chi^{2}=9 \cdot 88, \mathrm{df}=2, \mathrm{p}=0 \cdot 007\right)$, indicating that the effects of ketanserin on mortality from all causes depended on treatment with diuretics. This statistical interaction suggested that there was an adverse effect when ketanserin and potassium losing diuretics were taken together but that this effect did not occur with ketanserin alone or in combination with potassium sparing diuretics. The effects of the interaction were even more clear when the data for the patients who received the trial treatment were analysed: the corresponding relative mortality was $87 \%$ for those not taking diuretics, $76 \%$ for those taking potassium sparing diuretics, and $313 \%$ for those taking potassium losing diuretics (table IV).

In a further analysis all the deaths from vascular causes were classified as sudden or non-sudden by an observer who was unaware of the patients' treatment. Table IV shows that the excess of deaths in the ketanserin group taking potassium losing diuretics did not seem to be explained by an increase in the proportion of sudden deaths, although this finding has

TABLE IV-Total number of sudden and non-sudden deaths in patients taking ketanserin and piacebo according to whether they were taking diuretics at randomisation

\begin{tabular}{|c|c|c|}
\hline & $\begin{array}{c}\text { Ketanserin } \\
(\mathrm{n}=1930)\end{array}$ & $\begin{array}{c}\text { Placebo } \\
(n=1969)\end{array}$ \\
\hline \multicolumn{3}{|l|}{ No diuretics } \\
\hline $\begin{array}{l}\text { No of patients } \\
\text { No of deaths } \\
\text { Deaths in patients receiving trial treatment }{ }^{\star} \\
\text { Sudden deaths in patients receiving trial } \\
\text { treatment }^{\star}\end{array}$ & $\begin{array}{r}1475 \\
51 \\
41 \\
17\end{array}$ & $\begin{array}{r}1525 \\
60 \\
49 \\
15\end{array}$ \\
\hline \multicolumn{3}{|c|}{ Treatment with potassium sparing diuretics } \\
\hline $\begin{array}{l}\text { No of patients } \\
\text { No of deaths } \\
\text { Deaths in patients receiving trial treatment } \\
\text { Sudden deaths in patients receiving trial } \\
\text { treatment }{ }^{\star}\end{array}$ & $\begin{array}{r}206 \\
18 \\
11 \\
3\end{array}$ & $\begin{array}{r}184 \\
17 \\
13 \\
3\end{array}$ \\
\hline \multicolumn{3}{|c|}{ Treatment with potassium losing diuretics } \\
\hline $\begin{array}{l}\text { No of patients } \\
\text { No of deaths } \\
\text { Deaths in patients receiving trial treatment } \\
\text { Sudden deaths in patients receiving trial } \\
\text { treatment }{ }^{\star}\end{array}$ & $\begin{array}{r}249 \\
35 \\
30 \\
16\end{array}$ & $\begin{array}{r}260 \\
15 \\
10 \\
5\end{array}$ \\
\hline
\end{tabular}

*Includes patients who died within one week after trial treatment was withdrawn. to be interpreted with caution because of the way the information was collected.

ANALYSIS OF SUBGROUPS EXCLUDING PATIENTS

TAKING POTASSIUM LOSING DIURETICS AND

ANTIARRHYTHMIC DRUGS

Because the excess of deaths among the patients allocated to treatment with ketanserin seemed to be due to an interaction with potassium losing diuretics a further analysis was performed excluding all the patients who received such diuretics at any time during the trial. Patients taking antiarrhythmic drugs were also excluded because of the recommendations of the ethical and safety committee. To explore any effect of ketanserin only patients who received the trial treatment were included in the analysis. In this subgroup there were 1514 patients who took ketanserin and 1557 who took placebo, and their characteristics at randomisation were similar. There were 65 end points in the ketanserin group compared with 87 in the placebo group, and figure 1 (bottom) suggests that this difference between the groups appeared only after about 270 days; it did not reach conventional levels of significance $(p=0 \cdot 12)$. Table III shows the number of patients in each group who had a primary or secondary event in each category. Altogether 196 patients in the ketanserin group had at least one event or died compared with 249 in the placebo group $(p=0.02)$. The total number of events was 232 and 329 , respectively. This comparison, however, included six patients taking ketanserin and 31 patients taking placebo who developed severe hypertension, which was a secondary event; when these were subtracted the apparent benefit of ketanserin was diminished $(p=0 \cdot 25)$. In table $\mathrm{V}$ patients are grouped according to whether they had no event, one event, or more than one event. The difference between the treatment groups was more obvious $(p=0.006)$. In particular, multiple events were less common in the ketanserin group. The total number of events was 232 in the ketanserin group and 329 in the placebo group: the number of primary events was 68 and 91 , respectively, and the number of secondary events, excluding recently developed severe hypertension, was 146 and 185 , respectively.

\section{EFFECT OF KETANSERIN ON THE CORRECTED}

\section{QT INTERVAL IN THE ELECTROCARDIOGRAM}

Because of the excess of deaths associated with combined treatment with ketanserin and diuretics we compared electrocardiograms taken at randomisation and after one year. Altogether 552 pairs of electrocardiograms were selected at random from patients not taking diuretics and compared with those of all 511 patients who were taking diuretics or antiarrhythmic drugs at randomisation. All electrocardiograms were analysed by an observer who was unaware of whether the patient was taking ketanserin or placebo. There were more electrocardiographic abnormalities ( $Q$ waves, bundle branch block, atrioventricular block, and ST-T changes) among the patients taking diuretics.

At randomisation the average corrected QT interval was significantly longer in patients taking diuretics $(417 \mathrm{~ms})$ than in those who were not $(410 \mathrm{~ms}$, $\mathrm{p}<0.001)$. In the patients taking ketanserin alone the corrected QT interval increased by a mean of $18 \mathrm{~ms}$ $(\mathrm{p}<0.001 v$ placebo alone $)$; when ketanserin was combined with potassium sparing diuretics the corrected QT interval was prolonged by $24 \mathrm{~ms}$ $(\mathrm{p}=0.2 v$ ketanserin alone), and when combined with potassium losing diuretics it was prolonged by $30 \mathrm{~ms}$ $(\mathrm{p}=0.04 v$ ketanserin alone and $\mathrm{p}=0.38 v$ ketanserin combined with potassium sparing diuretics).

Eight patients in the ketanserin group had a 
TABLE V-Number of patients who had no, one, or more than one event excluding those who had taken a potassium losing diuretic or an antiarrhythmic, or both, at any time between randomisation and the last visit

\begin{tabular}{|c|c|c|c|c|}
\hline & \multicolumn{2}{|c|}{ Intention to treat analysis } & \multicolumn{2}{|c|}{ Analysis of patients receiving trial treatment } \\
\hline & Ketanserin & Placebo & Ketanserin & Placebo \\
\hline \multicolumn{5}{|c|}{ No of non-fatal primary events†: } \\
\hline 0 & 1474 & 1510 & 1480 & 1513 \\
\hline 1 & 39 & 44 & 34 & 42 \\
\hline$\geqslant 2$ & 1 & 3 & 0 & 2 \\
\hline \multicolumn{5}{|c|}{ No of secondary events: } \\
\hline 0 & 1365 & 1386 & 1383 & 1392 \\
\hline 1 & 129 & 126 & 115 & 124 \\
\hline$\geqslant 2$ & 20 & 45 & 16 & 41 \\
\hline $\mathrm{p}$ Value ( $\chi^{2}$ test $)$ & \multicolumn{2}{|c|}{0.01} & \multicolumn{2}{|c|}{0.005} \\
\hline \multicolumn{5}{|l|}{ Total No of events: } \\
\hline & 1306 & 1316 & 1330 & 1322 \\
\hline 1 & 176 & 183 & 159 & 184 \\
\hline$\geqslant 2$ & 32 & 58 & 25 & 51 \\
\hline $\mathrm{p}$ Value $\left(\chi^{2}\right.$ test $)$ & \multicolumn{2}{|c|}{0.03} & \multicolumn{2}{|c|}{0.006} \\
\hline
\end{tabular}

^Includes patients who had an event within one month after ketanserin or placebo was withdrawn. †Numbers too small for statistical analysis. tiredness, oedema, dry mucosa, and increase in weight); conversely, evidence of impaired peripheral circulation was seen more often with placebo (trophic changes, numbness, skin infections, and symptoms of Raynaud's disease). Disturbance of sleep was also more common with placebo (fig 2).

Blood pressure-The reduction in blood pressure in the patients taking ketanserin was significantly greater than that in the patients taking placebo. Severe hypertension (diastolic pressure $>119 \mathrm{~mm} \mathrm{Hg}$ ) occurred in 17 patients taking ketanserin and 40 taking placebo $(\mathrm{p}<0.001)$.

Biochemical and haematological variables-No clinically relevant biochemical or haematological changes were seen.

Rebound phenomenon-Patients were advised to taper off the ketanserin or placebo over two weeks at the end of the study; some stopped treatment abruptly during the trial. No increase in the number of primary or secondary events or worsening of claudication was observed in the first month after treatment was stopped.

Compliance-After the trial had been completed ketanserin was assayed in stored samples of plasma from 105 patients who had taken this drug. Measurable amounts were found in all 93 patients who were still taking ketanserin; none was detected in the remaining 12 patients, who were known to have stopped taking ketanserin.

these patients died) had a corrected QT $>500 \mathrm{~ms}$. All of the patients who had a corrected QT interval $>500 \mathrm{~ms}$ and developed complications that were clinically important were also taking diuretics or antiarrhythmic drugs.

\section{ANALYSIS OF OTHER VARIABLES}

Withdrawals-Altogether $298(15 \%)$ of the patients taking ketanserin and $257(13 \%)$ of those taking placebo stopped taking the drugs before the end of the trial. Three hundred and seventeen $(57 \%)$ of these withdrawals were because of the recommendations of the ethical committee. In addition, ketanserin was withdrawn from $106(5 \%)$ patients and placebo from $83(4 \%)$ patients because of side effects. All patients who were withdrawn from treatment were followed up until the end of the trial.

Complaints - One or more complaints were made by $1236(64 \%)$ of the patients taking ketanserin and by $1173(60 \%)$ of those taking placebo. The known side effects of ketanserin were confirmed (dizziness,

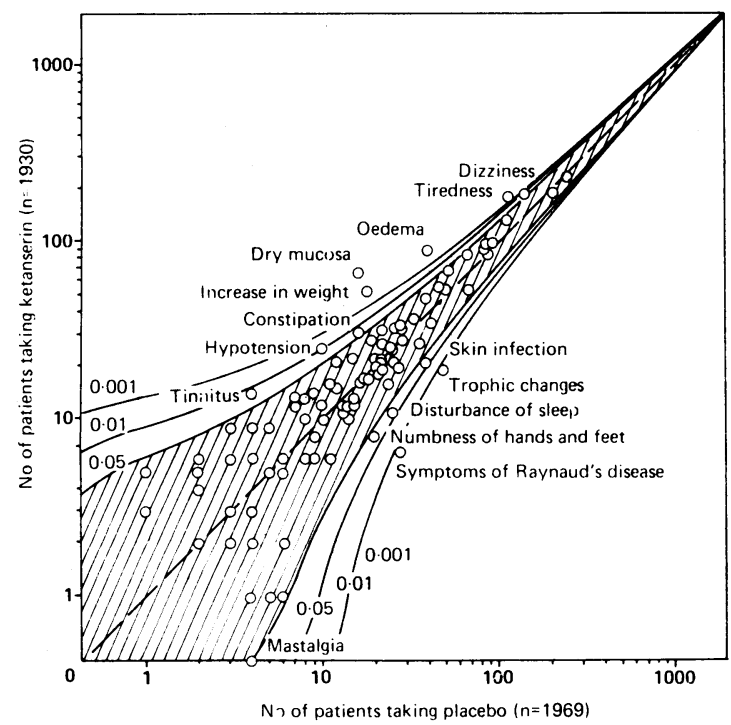

FIG 2-Prevalence-contrast diagram according to $P \mathcal{F}$ Lewi. ${ }^{21}$ Each dot represents a complaint. Complaints in shaded area are not significantly different between treatments; outside shaded area they are at $0.05,0.01$, or 0.001 (two tailed) level of significance ( $\chi^{2}$ test). Those found above the diagonal line were seen more commonly with found above the diagonal line were seen more commonly with
ketanserin, while those below the line were more common with placebo

\section{Discussion}

Whether aspects of platelet function that are mediated by serotonin have any relevance to thrombosis is not known. Because ketanserin inhibits platelet aggregation induced by serotonin and also prevents vasoconstriction there seemed to be good theoretical reasons to suppose that it might reduce cardiovascular mortality and morbidity in high risk patients such as those with claudication. The overall results of the trial, however, failed to show a protective effect of ketanserin.

The harmful interaction between ketanserin and potassium losing diuretics, which resulted in an excess of deaths, was disturbing. Ketanserin has been shown in this trial and in other studies to prolong the corrected QT interval ${ }^{1213}$ to an extent that is dose but not time dependent (J Symoens, unpublished data). Our results indicated that the use of diuretics was also associated with prolongation of the corrected QT interval. Evidence from previous studies suggests that potassium losing diuretics can cause various ventricular ectopic rhythms, often complex in character, and that the prevalence of such ventricular ectopy is inversely related to serum potassium concentration. ${ }^{14}$ is The delay in myocardial repolarisation caused by ketanserin at the high dose used in this trial (40 mg three times a day) perhaps led to a worsening of ventricular arrhythmias caused by the reduction in the potassium concentration that was induced by the potassium losing diuretics.

The safety of diuretics remains a matter of debate. In the multiple risk factor intervention trial the patients given special intervention fared slightly worse than those who received usual care. This may have been due to a harmful effect of diuretics in a subgroup of patients who had electrocardiographic evidence of cardiac disease at randomisation. ${ }^{16}$ The beneficial effects of even higher doses of potassium losing diuretics in the Medical Research Council trial of mild hypertension seemed to disprove this hypothesis, ${ }^{17}$ though the benefit from treatment shown in this study was a reduction in strokes rather than in myocardial infarction. In the Medical Research Council trial a reduction in myocardial infarction resulting from a 
lowering of blood pressure may have been offset by an increase in sudden deaths due to arrhythmias. The European working party study of hypertension in the elderly showed a significant reduction in death from myocardial infarction. ${ }^{18}$ This study was unusual in that a potassium sparing diuretic was used (hydrochlorothiazide with triamterene). In another trial there were significantly fewer deaths from myocardial infarction among hypertensive men taking metoprolol than among those taking thiazide diuretics. ${ }^{19}$ Our results may indicate that ketanserin, at the dose used, accentuates an underlying harmful effect of potassium losing diuretics that is not present with potassium sparing diuretics. A similar interaction has been described when potassium losing diuretics were combined with the $\beta$ blocker sotalol, which also prolongs the corrected QT interval. ${ }^{20}$ The interaction might also occur with other drugs that prolong the corrected QT interval.

When patients treated with potassium losing diuretics or antiarrhythmic drugs, or both, were excluded from our analysis patients treated with ketanserin had a slightly lower incidence of primary events than patients treated with placebo. This difference became statistically significant when secondary events were included in the analysis, although this observation must be viewed with caution as it derived from a secondary analysis of a subgroup of the randomised patients. When the trial was designed the number of end points expected was overestimated; furthermore, the interaction with potassium losing diuretics was not expected. Thus the trial neither confirmed nor refuted the hypothesis, and a further trial is required to determine whether ketanserin prevents cardiovascular complications.

Participants in the study were as follows:

Australia: P Blombery, Prahran; A Bray, Newcastle; D Effeney, Woolloongabba; J Harris, Camperdown; D Hunt, Parkville; R Lusby, Concord; G Mathews, T Morgan, Melbourne; M McGrath, Darlinghurst; J Royle, Heidelberg; J Walsh, Bedford Park; Belgium: J P Barroy, J L Locufier, R Van Gestel, J C Wautrecht, J P Dereume, Brussels; D Clement, D Duprez, Ghent; J De Crée, Merksem; J De Leersnijder, P Werbrouck, Duffel; P Depuydt, G Holvoet, Ostend; G Dereume, Tournai; G Dewaele, Roeselare; J Van Overbeke, G Van der Tempel, Aalst; R Verhaeghe, J Vermylen, Leuven; Bulgaria: T Arsov, S Jordanov, A Deutschinoff, V Batchvarova, L Grosdinski, T Mileva, M R Dimitrova, C P Kotceva, Sofia; Canada: H W Beattie, Hamilton; S A Carter, Winnipeg; P Cartier, J Leclerc, A A Page, Montreal; Y Douville, Quebec; J R Gutelius, Kingston; K A Harris, London; France: J Barrier, Nantes; F Becker, Dijon; O Blétry, R Cristol, Paris; H Boccalon, R Biermé, Toulouse; J Challan-Belval, Strasbourg; B Devulder, Lille; A Franco, Grenoble; L Guillevin, Bobigny; J L Guilmot, Tours; R Luccioni, I Juhan-Vague, Marseilles; J Ninet, Lyons; C Schmidt, Nancy; J M Serise, Bordeaux; Germany: $M$ Cachovan, Bad-Bevensen; C Diehm, Heidelberg; K Held, Göttingen-Weende; V Hossmann, U Alt, Köln-Merheim; D Klaus, Dortmund; A Leyhe, Marburg; G Rudofsky, Ulm; H Rieger, W Schoop, Engelskirchen; E Volger, Bad Wörishofen; Hungary: Gy Jambor, J Gati, T Samu, A Nemes, I Mogany, Gy Acsády, M Szirtes, V Kristof, L Urai, I Kolonics, P Szemeredi, Budapest; T Kiss, Gy Webber, S Peter, Pécs; E Mesko, I Bekesi, J Nemet, Zs Pecsvaradi, Kerepestarcsa; Italy: F Balsano, C Caliendo, P Fiorami, F Violi, Rome; S Coccheri, V de Rosa, Bologna; I Corea, S Berioli, Perugia; F S Feruglio, M Fisicaro, Trieste; A Libretti, M Catalano, Milan; F Rengo, V Canonico, Naples; A Strano, A Pinto, Palermo; The Netherlands: J D Banga, J W N Akkerman, Utrecht; C M A Bruyninckx, Eindhoven; H P C Donders, Enschede; W F Eggink, Arnhem; B C Eikelboom, J R M van der Sijp, Nieuwegein; P Jörning, J

Köhlen, R Bekkers, R S Reneman, Maastricht; M C Kerdel, Zwolle; H P J Van Houtte, C H A Wittens, Heerlen; G M J Widdershoven, J Viersma, Sluiskil; Norway: B BuggeAsperheim, H P Naess, Arendal; H A Dedichen, K Aartun, A Kroese, E Stranden, Oslo; J E Fossdal, Stavanger; T
Hammelbo, Kristiansand; S Haram, Foerde; G Haus, Skien; B Hoeivik, B Mjaaset, L Vasli, Nordbyhagen; J Isotalo, Hammerfest; O Lauen, L E Moeistad, Fredrikstad; A Nilsen, Moss; E Normann, Toensberg; A J Trippestad, Bergen; Sweden and Finland: B Arneklo-Nobin, Lund; D Bergkvist, Malmö; S Bygdeman, Stockholm; G Claes, Boras; R Edin, Varberg; E Einarsson, Eksiö; I Hagenfeldt, Ängelholm; T Hallböök, Skövde; J Holm, B Risberg, Gothenburg; P Konrad, Kalmar; M Lepäntalo, Helsinki; B Lindberg, Halmstad; J Lundvall, Växiö; P Ohlin, G Plate, Helsingborg; G Persson, Lund; $T$ Troeng, Karlskrona; Switzerland and Austria: W Blättler, Zürich; B Krähenbühl, H Bounameaux, Geneva; F Mahler, Bern; M Monti, Lausanne; H Denck, $H$ Raynoschek, H Partsch, H Sinzinger, J Kaliman, J Slany, Vienna; United Kingdom: K Burnand, P Dandona, J Dormandy, P Reddy, J D Lewis, B J Pardy, J Scurr, London; J Edwards, Carshalton; J Hosie, P Leiberman, G Lowe, G MacBain, J Smith, Glasgow; E Housley, Edinburgh; G Jantet, Middlesex; J R A Mitchell, D Sandler, Nottingham; I Schraibman, Rochdale; R A P Scott, Chichester; R Taylor, Epsom; D Wilkins, B P Bliss, Plymouth; United States: W Blackshear, Tampa; M Creager, Boston; B Cutler, Worchester; E Kwasnik, West Roxbury; J Porter, Portland; H Schnaper, South Birmingham; G Sethi, Asheville; J Spittell, Rochester; D Sumner, Springfield; J Yao, Chicago; J Young, Cleveland.

Members of the executive committee were $M$ Verstraete (chairman), Leuven; J Dormandy, London; M G Bousser, Paris; J R Hampton, Nottingham.

Members of the ethical and safety committee were D G Julian (chairman), Newcastle upon Tyne; N Browse, M Harrison, London; T C Chalmers, Boston; R Doll, Oxford; C Furberg, Winston Salem

Members of the protocol and evaluation committee were $\mathrm{H} \mathrm{J} \mathrm{M}$ Barnett, London, Canada; A Bollinger, Zürich; C J Bulpitt, J F Goodwin, S J Pocock, London; M L Dyken, Indianapolis; V Dzau, N Hollenberg, Boston; H Kulbertus, Liège; J I S Robertson, Hong Kong, Beerse; O Thulesius, Safat; C P Warlow, Edinburgh.

National coordinators were Gy Acsády, Budapest; F Balsano, F Violi, Rome; W Birkenhäger, P W de Leeuw, Rotterdam; P Blombery, Melbourne; O Blétry, P Godeau, Paris; D Clement, D Duprez, Ghent; J Coffman, Boston; A Deutschinoff, V Petrov, Sofia; J Dormandy, London; B Krähenbühl, Geneva; F Mahler, Berne; P Ohlin, G Plate, Helsingborg; H Rieger, W Schoop, Engelskirchen; E Stranden, Oslo; A G G Turpie, Hamilton; J Young, Cleveland.

Trial monitors were R Amstein, Baar; G Assogna, Rome; $M$ Csukas, Budapest; R Fisher, Neuss; B Fraitag, Paris; S Gould, J Turner, Grove; R J Grégoire, Mississauga; G Krastev, Sofia; W Loisch, Vienna; B Lundgren, Västra Frölunda; A K Olsen, Oslo; G Sieben, Beerse; J Smakman, Goirle; P L Whyatt, Sydney; B Bohanek, Piscataway.

Statistics centre: G D Murray, Glasgow.

Data management and processing centre: J Symoens, M Janssens, P Lewi, Beerse.

1 Lingjaerde O. Platelet uptake and storage of serotonin. In: Essman WB, ed. Serotonin in health and disease. New York: Spectrum, 1977:139-99.

2 Utsunomiya T, Krausz MM, Shepro O, Hechtman HB. Prostaglandin contro of plasma and platelet 5-hydroxytryptamine in normal and embolized animals. Am F Physiol 1981;141:H766-71.

3 Heistad DD, Armstrong ML, Marcus ML, et al. Augmented responses to vasoconstrictor stimuli in hypercholesterolemic and atherosclerotic monkeys. Circ Res 1984;54:711-8.

4 Leysen JE, Awouters F, Kennis L, et al. Receptor binding profile of R41468, a novel antagonist at 5-HT 2 receptors. Life $S c i$ 1981;28:1015-22.

5 Bogar L, Matrai A, Walker RT, et al. Haemorheological effects of a $5-\mathrm{HT}_{2}$ receptor antagonist (ketanserin). Clinical Hemorheology 1985;5:1 15-21.

6 Vanhoutte P, Amery A, Birkenhaeger W, et al. Serotonergic mechanisms in hypertension: focus on the effects of ketanserin. Hypertension 1988;11: $111-33$

7 Clement D, Duprez D. Effect of ketanserin in the treatment of patients with intermittent claudication: results from 13 placebo-controlled parallel grou studies. F Cardiovasc Pharmacol 1987;10(suppl 3):S89-95.

8 Thulesius $\mathrm{O}$, Lundvall $\mathrm{J}$, Kroese $\mathrm{A}$, et al. Ketanserin in intermitten claudication: effect on walking distance, blood pressure, and cardiovascula complications. F Cardiovasc Pharmacol 1987;9:728-33.

9 Coffman JD. Intermittent claudication: not so benign. Am Heart 7 1986;112: $1127-8$.

10 Dormandy JA, Mahir M, Balsano F, et al. Fate of the claudicant. European foumal of Cardiovascular Surgery (in press).

11 Brugada P, Wellens HJJ. Sudden cardiac death: a myocardial problem. In Brugada P, Wellens HJJ, eds. Cardiac arrhythmias: where do we go from here? Brugada P, Wellens HJJ, eds. Cardiac arrhythmias: where
New York: Future Publishing Company, 1987:391-400.

12 Saman S, Thandroyen F, Opie LH, Serotonin and the heart: effects of ketanserin on myocardial function, heart rate and arrhythmias. $\mathcal{F}$ Cardiovas Pharmacol 1985; 7(suppl 7):S70-5. 
13 Singh BN, Nademanee K, Symoens J, Janssens M. Ketanserin and QTc prolongation. Eur Heart $\mathcal{F}$ 1987;8:667-8.

14 Medical Research Council Working Party on Mild to Moderate Hypertension. Ventricular extrasystoles during thiazide treatment: substudy of MRC mild hypertension trial. Br Med f 1983:287:1249-53.

15 Ragnarsson J, Hardarson T, Snorrason SP. Ventricular dysrhythmias in middle-aged hypertensive men treated either with a diuretic agent or a B-blocker. Actu Med Scand 1987;221:143-8.

16 Cohen JD, Neaton JD, Prineas RJ, Daniels KA. Diuretics, serum potassium and ventricular arrhythmias in the multiple risk factor intervention trial. and ventricular arrhythmias in

17 Medical Research Council Working Party. MRC trial of treatment of mild hypertension: principal results. Br Med J 1985;291:97-104.
18 Amery A, Birkenhaeger W, Brixko P, et al. Mortality and morbidity results from the European working party on high blood pressure in the elderly trial. Lancet 1985; i: 1359-64.

19 Wikstrand J, Warnold I, Olsson G, Tuomilehto J, Elmfeldt D, Berglund G, on behalf of the advisory committee. Primary prevention with metoprolol in patients with hypertension. Mortality results from the MAPHY Study. ҰAMA 1988:259:1976-82.

20 McKibbin JK, Pocock WA, Barlow JB, et al. Sotalol, hypokalaemia, syncope, and torsade de pointes. British Heart $\mathcal{f} 1984 ; 51: 157-62$.

21 Lewi PJ. Graphical assessment of statistical significance and clinical-biological relevance. Drug Development Research (in press).

(Accepted 16 November 1988)

\section{Comparison of starting antiemetic treatment 24 hours before or concurrently with cytotoxic chemotherapy}

\author{
C J Williams, C Davies, M Raval, J Middleton, \\ J Luken, B Stone
}

\section{CRC Medical Oncology \\ Unit, Southampton \\ General Hospital, \\ Southampton SO9 4XY \\ C J Williams, DM, senior \\ lecturer \\ C Davies, medical student \\ M Raval, medical student \\ J Middleton, SRN, \\ chemotherapy sister \\ J Luken, SRN, chemotherapy \\ sister}

B Stone, data coordinator

Correspondence to:

Dr Williams.

BrMed f 1989;298:430-1 parison of two different schedules.
Two of the main side effects of cytotoxic chemotherapy are nausea and vomiting, which may be severe enough to cause some patients to abandon effective treatment. Although antiemetics can ameliorate the degree of nausea and vomiting, none is universally effective, and emesis is often rated by patients as their most distressing side effect.' ${ }^{\prime}$ Recent trials have used combinations of antiemetics whose mechanism of action is likely to be different. Both domperidone (a dopamine antagonist) and dexamethasone (mechanism unknown) have useful antiemetic activity. They and other drugs have been used in various schedules, starting the night before, hours before, or concurrently with chemotherapy. We made a randomised com-

\section{Patients, methods, and results}

Patients receiving chemotherapy as outpatients were selected for inclusion; the nature of the trial was explained, and all gave oral consent. Patients were receiving combination chemotherapy with a regimen of either: moderate emetic potential (cyclophosphamide, doxorubicin, vincristine, and prednisolone; or procarbazine, etoposide, prednisolone, and doxorubicin; or vincristine, doxorubicin, and prednisolone); or mild emetic potential (chlorambucil, vinblastine, procarbazine, and prednisolone; or cyclophosphamide and etoposide). Patients were classified according to the emetogenic potential of the chemotherapy and whether they had $(n=20)$ or had not $(n=20)$ received prior chemotherapy. All prior chemotherapy had been of low emetic potential (often oral alkylating agents).

All patients began treatment 24 hours before starting chemotherapy. Those randomised to active treatment received oral domperidone $20 \mathrm{mg}$ and dexamethasone $4 \mathrm{mg}$, both six hourly, for 24 hours before chemotherapy. Patients randomised to the control group received matched placebos in the same schedule. When the cytotoxic chemotherapy was given both groups took oral domperidone $20 \mathrm{mg}$ and dexamethasone $4 \mathrm{mg}$ six hourly for 24 hours.

Potential side effects were assessed on a linear analogue scale. The scale was explained to patients, who completed it 24 hours after starting cytotoxic chemotherapy and returned it to the researchers. Patients rated their nausea, vomiting, and 18 other potential side effects of chemotherapy or the antiemetics on a $100 \mathrm{~mm}$ line. Results were analysed with the Mann-Whitney $U$ test $^{2}$ as the unpaired data did not conform to a normal distribution. Confidence intervals were calculated with the method of Campbell and Gardner. ${ }^{3}$ Low scores on the assessment scales indicated little toxicity and high scores severe side effects.

The table shows the ranked scores for nausea in the two groups, the difference being significant $(p=0 \cdot 001)$. As highly emetogenic cytotoxic drugs, such as cisplatin, were not used a high proportion of patients $(40 \%)$ reported no vomiting. Despite this most patients with severe vomiting were in the placebo group. Median scores were 1 for the active group and 14.5 for the placebo group. The estimated difference was $9.99(95 \%$ confidence interval 0 to $14 \cdot 9 ; p=0 \cdot 02)$.

Ranked scores on linear analogue self assessment scale for nausea in patients randomised to active antiemetic treatment $(n=20)$ or placebo $(n=20)^{\star}$

\begin{tabular}{ccc|clc}
\hline Score & Treatment & Rank & Score & Treatment & Rank \\
\hline 0 & Active & $3 \cdot 5$ & 22 & Active & 21 \\
0 & Active & $3 \cdot 5$ & 25 & Active & 22 \\
0 & Active & $3 \cdot 5$ & 30 & Placebo & $23 \cdot 5$ \\
0 & Placebo & $3 \cdot 5$ & 30 & Active & $23 \cdot 5$ \\
0 & Active & $3 \cdot 5$ & 35 & Placebo & 25 \\
0 & Active & $3 \cdot 5$ & 38 & Placebo & 26 \\
2 & Active & 7 & 42 & Placebo & 27 \\
7 & Active & 8 & 45 & Placebo & 28 \\
8 & Active & 9 & 50 & Placebo & $29 \cdot 5$ \\
10 & Placebo & $10 \cdot 5$ & 50 & Placebo & $29 \cdot 5$ \\
10 & Active & $10 \cdot 5$ & 52 & Active & 31 \\
12 & Placebo & 12 & 60 & Placebo & 32 \\
13 & Active & 13 & 64 & Placebo & 33 \\
15 & Placebo & 15 & 68 & Placebo & 34 \\
15 & Active & 15 & 71 & Placebo & 35 \\
15 & Placebo & 15 & 74 & Placebo & 36 \\
18 & Active & 17 & 76 & Active & 37 \\
20 & Active & $18 \cdot 5$ & 82 & Placebo & 38 \\
20 & Active & $18 \cdot 5$ & 86 & Placebo & 39 \\
21 & Active & 20 & 95 & Placebo & 40 \\
\hline
\end{tabular}

Active range $0-76$, median score 14 , sum of ranks $(A)=288 \cdot 5$; placebo range $0-95$, median score 50 , sum of ranks $(P)=531 \cdot 5$.

Estimate of difference between $A$ and $P=31 \cdot 50 ; 95 \%$ confidence interval for difference 14.9 to $49 \cdot 0 ;$ Mann-Whitney U test $\mathrm{p}=0.001$.

*Other variables measured were vomiting, drowsiness, concentration, perception of time, perception of distance, feelings of dissociation, coordination, dizziness, dry mouth, heartburn, diarrhoea, constipation, palpitations, thirst, polyuria, restlessness, blurred vision, tremor, mood, and appetite.

The differences between the groups for the 18 other variables measured were not significant, though moderately large increases in scores were seen for thirst, dry mouth, and restlessness in the placebo group, which may have resulted from the effects of increased emesis.

\section{Comment}

Our trial shows that a 24 hour pretreatment with domperidone and dexamethasone significantly reduced nausea and vomiting in patients receiving mild to moderate emetogenic chemotherapy. This could be explained by the pharmacokinetics of the antiemetics used. Domperidone has a half life of about $7 \cdot 5$ hours and dexamethasone of three to four hours. As the drugs were given six hourly for the 24 hours before chemotherapy accumulation would have taken place. ${ }^{+}$Steady state concentrations would have been approached in the six hours after administration of the 